\title{
Tubularized Incised plate(Snodgrass)urethroplasty as the Surgical Technique of Choice for Repair of Distal and Midshaft Hypospadias in Tikrit Teaching Hospital Mazin A Yadigar (FIBMS,PhD) ${ }^{1}$, Yasir I Abbas (FIBMS,PhD) ${ }^{2}$ and Fawzi Salih Shehab Aljomaily (FIBMS,PhD) ${ }^{3}$
}

\begin{abstract}
Background: The Snodgrass technique is a widely accepted method for hypospadias repair. Snodgrass has a urethroplasty of tubularized incised plate (TIP) type for repair of distal penile hypospadias. It was with encouraging results and also applied to hypospadias of proximal type.

Objective:To evaluate Conducting surgical techniques performed to repair the submicillator. Patients and Methods: In this study, we follow the patient post operatively within three months after performing this technique and notice its final outcome with respect to postoperative complications and outcome, with emphasis on meatal stenosis, fistula formation, residual chordee and penile torsion.

Results: We reviewed the results of 60 cases treated by Snodgrass urethroplasty between March 2012 and February 2014at the urological department in Tikrit Teaching Hospital. In this study, performed Snodgrass technique on 60 cases for primary hypospadias, The boys age at time of operation ranged from 18 months to 14 years. The mean age of the children was 5 years. Complications occurred in 8 patients $(13.3 \%)$. Aurethrocutaneous fistula occurred in 6 patients $(10 \%)$. three $(5 \%)$ of these patients with u.c.fistula associated with meatal stenosis . one patient develop meatal stenosis only and Penile torsion was recorded postoperatively in one patient also.

Conclusion: A shorter urethral plate incision, use of a lateral and preputial dartos flap to cover the neourethra and more extensive skin degloving in Snodgrass urethroplasty reduce the rate of complications.

Keywords: TIP(Tubularized Inncised plate),UCF(Urethro Cutaneous Fistua.

Corresponding Author: mazin_yadigar78@yahoo.com

Received: $21^{\text {th }}$ December 2017

Accepted: $21^{\text {th }}$ January 2018

https://doi.org/10.26505/DJM

${ }^{1,2,3}$ College of Medicine - University of Tikrit - Salahaddin - Iraq.

\section{Introduction}

Hypospadias is the commonest congenital malformations of the genital system of male gender. Its incidence in USA in 2001 was 1 per two-three hundred male live births, [1] in comparison Netherlands incidence in 2002 was 3 over thousand male live births[2].

Abnormal position of the urethral meatus on the ventral penile surface, may be associated with ventral curvature of the penis (chordee). In addition to the functional problems caused by Hypospadias, psychological problems for patients and their parents. Many methods
\end{abstract}


Tubularized Incised plate(Snodgrass)urethroplasty as the Surgical Technique of Choice for Repair of

have been innovated for hypospadias repairing, but none was considered the standard method. Snodgrass has a urethroplasty of tubularized incised plate (TIP) type for repair of distal penile hypospadias.

It was with encouraging results and also applied to hypospadias of proximal type. $(3,4)$ A split of longitudinal type, the plate of urethra innovated by Snodgrass represents a big advance in preserving surgery of urethral plate-, permitting a type free tension urethral plate tubularization to form a neourethra of sufficient size. The technique is now widely accepted.(5)The principal steps are a deep longitudinal incision of the urethral plate to allow tubularization, and addition of a layer between the neourethra and the overlying skin to avoid urethra cutaneous fistula $[6,7]$. The surgical goals of hypospadias repair are full straighteningof the penis, formation of a hairless urethra of uniform caliberand adequate size, meatus positioning at the glans tip of the and normal penile appearance with minimum complications. Nevertheless, complications such as fistula, meatal stenosis, urethral flap necrosis and dehiscence are still encountered.

Surgeons use small variations in the technique to limit the complications. The distal limit of the deep longitudinal incision may be either the mid-glans or glans tip. The covering flap of the neourethra is usually raised from the preputialskin; however, this may result in penile torsion and devascularizationof the preputial skin that is often used in reconstruction of the penile skin
[8].A ventral dartos flap has been used to cover the neourethra in order to avoid these complications. Despite such modifications, complications of hypospadias repair, such as fistulae, urethral stricture, meatal stenosis, penile torsion, persistent chordee, infections and wound dehiscence, are still reported[9].

\section{Patients and Methods}

A prospective randomized research was done at the Urologic department in Tikrit Teaching Hospital from March 2012 to February 2014. Sixty cases with isolated hypospadias of primary distal type were taken in research after parental informed consent were taken paper.

Patients with recurrent problems, patients with defects of proximal type, and cases that dropped from program of follow-up were not taken from this study. The cases ages were of 1.5 - 14 years. All cases were evaluated regarding age, family history, types of anomalies in association, hypospadias types, associated chordee and circumcision history, and repair were done for them using then the same surgeon did method of Snodgrass.

All surgical procedures were done by the authorizing the same key steps. When a TIP repair is done a U-shaped skin incision is made along the edges of the urethral plate and the penis is degloved. Urethral plate is widened by a midline incision along its length and then tubularized over a stent of (6$8 \mathrm{Fr}$ ) size. A subcutaneous tissue of pedicle is dissected from penile skin (ventral or dorsal) used in covering the neourethra. At the end, the wings of glanular, collar of mucosa and penile skin ventral aspect are closed in 
Tubularized Incised plate(Snodgrass)urethroplasty as the Surgical Technique of Choice for Repair of

Distal and Midshaft Hypospadias in Tikrit Teaching Hospital

Mazin A Yadigar

midline. After the completion of repair, a urethral stent was fixed to the glans penis with a $3 / 0$ silk suture. Urinary diversion by suprapubic draining catheter was performed in some patient.

All patients were admitted to the hospital postoperatively and usually discharged after the catheter was removed between the $7 \mathrm{rd}$ and 10th day postoperatively. A vertically oriented slit, oval meatus and a conical shape of glanular with a direct urine stream were indicators for favorable outcome. Cases were examined at visits of follow-up after a month and these visits included searching for complications, stream of urine, calibration, and the site and shape of meatus

\section{Results}

Sixty patients were operated upon by tubularized incised plate. The age distribution range from 1.5-14 years ,46cases(76.65\%) were preschool and 14 cases(23.35\%) were school age.A positive family history was found in 6 cases(10\%),from these first degree relative was positive in 4 cases $(7 \%)$ and second degree relative in 2 cases(3\%).Subcoronal type in 30 cases $(50 \%)$,distal penile hypospadias in 15 cases $(25 \%)$,midshaft hypospadias in 9 cases $(15 \%)$,coronal type in 5 case $(8.3 \%)$,and penoscrotal hypospadias 1 case $(1.7 \%)$.Unilateral undesended testes in 3 cases $(5 \%)$. Chordee (mild) in 9 cases $(15 \%)$.Circumcision in 4 cases $(6.6 \%)$.
Regarding

acute

postoperative complications of, there was absence of obvious hematoma or hemorrhage only in one patient with bleeding of minor degree and good dressing is sufficient to control bleeding. Spontaneously resolved postoperative edema, was reported in 25 patients.

UCF occurred in $6(10 \%)$ cases (meatal stenosis occurred in $50 \%$ of cases). All cases had a single UCF, except 1 case, who had 2 fistulae. size of fistula was of diameter of 3 $\mathrm{mm}$ and less in all cases. Whole number of patients with UCF came in the period of first two months postoperatively. repairing surgical, after around nine to twelve months, was successful in all cases. Only four patients (7\%) meatal stenosis occurred, and regular urethral dilatation effective for all of them. Postoperative wound infection occurred in two cases and was treated by non surgical methods by simple care of wound. Parental satisfaction regarding cosmetic outcome occurred in all patients with complications free postoperativly.

Excluding cases with fistulae and/or stenosis of meatus, all cases voided with a forward straight single stream and had a meatus of slit-like at the tip of normally looking glans. Considering surgeon view were good for cosmetic outcomes obtained in 50 patients $(83.5 \%)$ while favorable cosmetic outcome in 10 patients $(16.5 \%)$. 
Tubularized Incised plate(Snodgrass)urethroplasty as the Surgical Technique of Choice for Repair of

Table (1): Types of Hypospadias.

\begin{tabular}{||c|c|c||}
\hline \hline Type & Number & $\%$ \\
\hline \hline Subcoronal & 30 & $50 \%$ \\
\hline \hline Distal penile & 15 & $25 \%$ \\
\hline \hline Midshaft & 9 & $15 \%$ \\
\hline \hline Coronal & 5 & $8.3 \%$ \\
\hline \hline Penoscrotal & 1 & $1.7 \%$ \\
\hline \hline & 60 & $100 \%$ \\
\hline
\end{tabular}

\section{Discussion}

Till now, more than 200 described surgical operations or modified methods have innovated to treat hypospadias patients but no single surgical method has been regareded as panacea for all hypospadias cases and it has represent the most challenging obstacles in surgical urology.

Nonetheless, high success rate obtained in the field as staged repairs paved the way to single-stage surgery that stated by Asopa et al [12] and Duckett [13,14]. At the end of the 20th century, Snodgrass advocated a versatile TIP surgery for most patients of hypospadias repair, which gave wanted preferable functional \& cosmetic outcome $[15,16]$.

TIP repair is the preferred technique in distal hypospadias [17]. The appropriate age for repair of hypospadias is 6-18 months [18]. overall surgical success depends on the presence of, vascularized and healthy tissue cover over the neourethra [19]. Snodgrass and Sozubir found that the flap of dartos pedicle may be used in covering the neourethra and this method was adovacated in our research. [21]. This study found that positive family history was found in 9 cases $(15 \%)$, from those 6 cases $(10 \%)$ was in the first degree relative and 2 cases (3\%) in the second degree relative. This fact was agreed with other studies which shows that genetic factors play a major role in incidence of hypospadias between relatives[22].

We have 6 cases (10\%) had been circumcized before they consult our center for hypospadias repair. In those patients the technique was difficult and the tissue is inadequate to perform a good flap,but manage those cases by degloving the penis to the penoscrotal junction and partial moblization of the short flap.

Hypospadias surgery followed by complications in higher number of cases in comparison with other reconstructive surgery [25].Fistulae and meatal stenosis are the most common complications with a slightly low incidence. Fortunately, few cases of urethral strictures followed Snodgrass technique. Snodgrass innovate a procedure consist of longitudinal incision on urethral groove and this permits free tension tubularization of the narrow plate of urethral to give a neourethra of good size. some histological researches stated that the plate of urethral consist of epithelium covering good vascularised connective tissue with very big nerve supply $[26,27]$. Snodgrass repair contain another important step is the interposition of a separating layer of subcutaneous tissue of 
Tubularized Incised plate(Snodgrass)urethroplasty as the Surgical Technique of Choice for Repair of

Distal and Midshaft Hypospadias in Tikrit Teaching Hospital

dartos between the covering skin closure and the neourethra. Wide dissection of a layer of dartos pedicle from the dorsal prepuce and shaft skin can impede skin blood supply that is used for resurfacing closure, and lead to loss and skin dehiscence. Ventral transposition \& obilization of the flap of dartos around a side of the shaft of penile may also lead to torsion of penis. Snodgrass repair has a success rate of $90 \%[28,29]$. TIP urethroplasty followed by complication in $6-16 \%$ of cases [30]. Meatal stenosis complicate UCF in $1-30 \%$ of cases and disruption of the repair and and infection in $7-10 \%$ in cases $[31,32]$. These rates are higher than the present study; which may be due to involvement of cases with more defects that are proximal and surgeries redo. This study has success rate (patients without complications) was $85 \%$ of cases, and whole rate of complication was $15 \%$ in 8 cases.

The present study outcomes are in accordance with results obtained by Tarkan et al. and Bhat and Mandal. Tarkan et al found that $8.3 \%$ of cases had UCF and meatal stenosis, and found that always the fistulae were single and of $5 \mathrm{~mm}$ and less in diameter and were successfully repaired [3334]. Tarkan et al also found that A fistula appeared thirty days month after repair of hypospadias in $74 \%$ of cases, and $85 \%$ of cases had only a fistula [35]. Mandal and Bhat found the fact of a clouser of [36]. reported that closure of fistula should be done after three to six. Successful fistula surgical repair were in all patients [37]. Anwar et al 2004 operated on 30 patient by
TIP technique with incidence of fistula reach up to $16 \%[38]$. Chenge 2002 report that fistula can be avoided by interposition of vasculardartos flap between the neourethra and skin. In our study we use vicryl as a suture material and even with this we have a good result. This types of suture material was used by other surgeon and give near the same results for all types of suture material. [39].Anwar Alhaji used vicryl with incidence of fistula about $16 \%$ [38].

TIP urethroplasty followed by meatal stenosis in 6.2 - $12 \%$, and most cases responded good to regular urethral dilatation [11]. Elbakry [40] found fact stated that postoperative regular calibration of urethra should be considered as an obvious part of urethroplasty of TIP form in prevention stenosis of meatus. This study goes with these results.

Bleeding \& hematoma occur in 3 cases $(5$ $\%$ ), and this complication occur in hypospadias surgury and no need for evacuation . Elbakry prefer evacuation of hematoma [41].

Three patient (5\%) developed stenosis and needed regular dilitation and 0ne case, require one calibration under general anasthesia, the rest of our patient not need dilitation or calibration ,this goes with other studies that calibration of urethra during follow up is routine procedure and decide who need just frequent calibration or regular dilitation [42].

In general we have excelentcosmotic result , near normal glans configuration, slit like meatus which is more cosmotic than 
Tubularized Incised plate(Snodgrass)urethroplasty as the Surgical Technique of Choice for Repair of

Distal and Midshaft Hypospadias in Tikrit Teaching Hospital

M.A.G.P.I. which give bifid glans and round opening \& this is confirmed by doctor $87 \%$ $\&$ family $70 \%$ this give us that cosmetics results is good .This goes with Selami who confirm that no other procedure releably create a vertical oriented meatus \& near normal configuratin of the glans[43].

\section{References}

[1]Baskin LS, Colborn T, Aimes K. Hypospadias and endocrine disruption: is there a connection? Environ Health Perspect 2001; 109: 1175-1183.

[2] Pierik FH, Burdorf A, Nijman JMR, et al. A high hypospadias rate in the Netherlands. Hum Reprod 2002; 17: 1112-1115.

[3]Brekalo Z, Kvesic' A, Nikolic' H, Tomic' D, Martinovic' V. Snodgrass' urethroplasty in hypospadias surgery in Clinical Hospital Mostar-preliminary report. CollAntropol 2007; 31(1): 189-193.

[4]Snodgrass W. Tubularized incised plate uretheroplasty for distal hypospadias. J Urol 1994; 151: 464-465.

[5] Snodgrass W. Changing concepts in hypospadias repair. CurrOpinUrol 1999; 9: 513-516.

[6]Zhou Y, Lu J, Takarashi G. Snodgrass procedure for primary hypospadius repair. J Urol 2002; 9: 215-218.

[7] Al-Hunayan AA, Kehinde EO, Elsalam MA, Al-Mukhtar RS. Tubularized incised plate uretheroplasty: modification and outcome. IntUrolNephrol 2003; 35: 47-52.

[8] El-Kassaby AW, Al-Kandari AM, ElZayat T, Shokeir AA. Modified tubularized incised plate urethroplasty for hypospadias repair: a long-term results of 764 patients. J Urol 2008; 71: 611-615.

[9] Snodgrass W, Koyle M, Manzoni G, Hurwitz R, Caldamone A, Ehrlich R. Tubularized incised plate repair for proximal hypospadias. J Urol 1998; 159: 2129-2131. [10] Asopa HS, Elhence EP, Atri SP, Bansal NK. One-stage correction of penile hypospadias using a foreskin tube, a preliminary report. IntSurg1971; 55(6): 435.440.

[11] Snodgrass WT. Tubularized incised plate hypospadias repair: indications, technique, and complications. Urology 1999; 54(1): 6-11.

[12] Snodgrass W, Patterson K, Plaire JC, Grady R, Mitchell ME. Histology of the urethral plate: Implications for hypospadias repair. J Urol2000; 164(3 Pt 2):988-9; discussion 989-990.

[13] Alexander S,Wilfried K, Ernst $H$. Trends in hypospadias surgery: results of a worldwide survey. EurUrol 2011; 60:11841189.

[14] Manzoni G, Bracka A, Palminteri E, Marrocco G. Hypospadias surgery when, what and by whom. Br J Urol 2004; 94:1188-1194.

[15] Bhat A. General considerations in hypospadias surgery. Indian J Urol 2008; 24:188-194.

[16] Sozubir S, Snodgrass W. A new algorithm for primary hypospadias repair based on TIP urethroplasty. J PediatrSurg 2003; 38: 1157-1161.

[17] Yerkes E, Adams M, Miller D, Pope JC IV, Rink RC, Brock JW III. Y-to-I wrap: use 
Tubularized Incised plate(Snodgrass)urethroplasty as the Surgical Technique of Choice for Repair of

of the distal spongiosum for hypospadias repair. J Urol 2000; 163:1536-1538.

[18] DuckettJW. “Hypospadias”. In: Walsh PC, et al., editor. Campbell's urology. 7th ed. Philadelphia: WB Saunders Co.; 1998. pp. 2093-2119.

[19] Erol A, Baskin LS, Li YW, Liu WH. Anatomical studies of the urethral plate: Why preservation of the urethral plate is important in hypospadias repair. BJU Int2000; 85(6): 728.734.

[20] Bleustein CB, Esposito MP, Soslow RA, Felsen D, Poppas DP. Mechanism of healing following the Snodgrass repair. J Urol 2001; 165(1): 277.279.

[21] EY, Vemulapalli SN, Kropp BP, Pope JC IV, Furness PD III, Kaplan WE, Smith DP. Snodgrass hypospadias repair with vascularized dartos flap: the perfect repair for virgin cases of hypospadias? J Urol 2002; 168: 1723-1726.

[22] Riccabona M, Oswald J, Koen M, Beckers G, Schrey A, Lusuardi L. Comprehensive analysis of six years experience in tubularised incised plate urethroplasty and its extended application in primary and secondary hypospadias repair. EurUrol 2003; 44:714-719.

[23] Yeap B, Mohan N. Hypospadias from the perspective of a single surgeon practice in Malaysia. Med J Malaysia 2008; 63:388390.

[24] Al Saied G, Gamal A. Versatility of tubularized incised plate urethroplasty in the management of different types of hypospadias: 5 years experience. Afr J PaediatrSurg 2009; 6:88-92.
[25] arkan S, Nihat A, Ali E, et al. Snodgrass hypospadias repair with ventral based dartos flap in combination with mucosal collars. EurUrol 2005; 47:879-884.

[26]Basharat A, Muhammad A, Faraz B. Comparative study of inverting sutureline versus over and over continuous suturing in hypospadias repair. J Ayub Med Coll Abbottabad 2009; 21:34-36.

[27]Al Saied G, Gamal A. Versatility of tubularized incised plate urethroplasty in the management of different types of hypospadias: 5 years experience. Afr J PaediatrSurg 2009; 6:88-92.

[28]Bhat A, Mandal A. Acute postoperative complications of hypospadias repair.

[29]Chung JW, Choi SH, Kim BS, Chung SK. Risk factors for the development of urethrocutaneous fistula after hypospadias repair: a retrospective study. Korean J Urol 2012; 53:711-715.

[30] Anwar -Ul -Hag ,Ilyas Bader et al : Tubularized incised plate urethroplasty of hypospadias .J of physician and surgeon pakistan .

[31]ChengEY,Vemulapallisn,etal:Snodogras s hypospadias repair wit vascularized dartos flap ,the perfect repair for virgin cases of hypospadias .JUrol 2002;168:1723-6.

[32]Elbakry A. Further experience with tubularized-incised urethral plate technique for hypospadias repair. BJU Int 2002; 89:291-29.

[33]Selami S.,W.snodograss. A new algorithm for primary hypospadiasrepair based on TIP urethroplasty. Journal of pediatric surgery am 2003;38:1157-61. 